\title{
BMJ Incidence of obstetric anal sphincter open injuries after training to protect the perineum: cohort study
}

\author{
Katariina Laine, ${ }^{1,2}$ Finn Egil Skjeldestad, ${ }^{3}$ Leiv Sandvik, ${ }^{4}$ Anne Cathrine Staff ${ }^{2,5}$
}

To cite: Laine $\mathrm{K}$

Skjeldestad FE, Sandvik L, et al. Incidence of obstetric anal sphincter injuries after training to protect the perineum: cohort study. BMJ Open 2012;2:e001649. doi:10.1136/bmjopen-2012001649

- Prepublication history and additional material for this paper are available online. To view these files please visit the journal online (http://dx.doi.org/10.1136/ bmjopen-2012-001649).

Received 11 June 2012 Accepted 4 September 2012

This final article is available for use under the terms of the Creative Commons Attribution Non-Commercial 2.0 Licence; see http://bmjopen.bmj.com

For numbered affiliations see end of article

\section{Correspondence to} Dr Katariina Laine; kattiksen@yahoo.no

\begin{abstract}
Objective: To compare the incidence of obstetric anal sphincter injuries (OASIS) in two time periods, before and after implementing a training programme for improved perineal support aimed at reducing the incidence of obstetric anal sphincter injuries. The secondary aim was to study incidence of obstetric anal sphincter injuries in subgroups defined by risk factors for OASIS.
\end{abstract}

Design: Population-based cohort study.

Setting: University hospital setting in Oslo, Norway.

Participants: Two cohorts of all delivering women in the largest hospital in Norway during two time periods (2003-2005 and 2008-2010) were studied. After excluding caesarean sections and preterm deliveries (< week 32), the study population consisted of 31709 deliveries, among which 907 women were identified with obstetric anal sphincter injury.

\section{Primary and secondary outcome measures:}

Incidence of OASIS in two time periods. Maternal, obstetrical and foetal risk factors for OASIS were collected from the hospital obstetric database. Univariate analyses and multivariate logistic regression analyses, presenting adjusted ODs for OASIS, were performed.

Results: The OASIS incidence was significantly reduced by $50 \%$, from $4 \%(591 / 14787)$ in the first time period to $1.9 \%(316 / 16922)$ in the second. This reduction could not be explained by changes in population characteristics or OASIS risk factors during the study years. The reduction of incidence of OASIS between the two study periods was consistent across subgroups of women; regardless of parity, delivery method and infant birth weight.

Conclusions: A marked reduction in the incidence of OASIS was observed in all studied subgroups of women after implementing the training programme for perineal protection. Further, this reduction could not be explained by the differences in patient characteristics across the study period. These findings indicate that the training programme with improved perineal protection markedly reduced the risk of OASIS.

\section{INTRODUCTION}

Obstetric anal sphincter injury is a serious maternal complication during a vaginal

\section{ARTICLE SUMMARY}

\section{Article focus}

- The present study compares obstetric anal sphincter injury in a large university hospital in two time periods (2003-2005 and 2008-2010), before and after implementing a perineum protection training programme to midwives and physicians to reduce the incidence of obstetric anal sphincter injuries.

- Incidence of obstetric anal sphincter injury in different subgroups of women defined by risk factors is presented.

- The incidence of obstetric anal sphincter injury was reduced between the two time periods.

\section{Key messages}

- The incidence of obstetric anal sphincter injuries can be reduced by implementing improved delivery techniques. Such injuries may cause persistent disabling anal incontinence symptoms.

- A significant and persisting reduction of incidence of obstetric anal sphincter injuries of $50 \%$ from the first study period to the second study period was obtained.

- The incidence of obstetric anal sphincter injuries was reduced similarly in all subgroups of women, and therefore we suggest that obstetrical interventions aiming at reducing the incidence of OASIS should be offered to all delivering women, not only to women in high-risk groups.

Strengths and limitations of the study

- Non-selected population of delivering women, large sample size.

- Validated institutional patient record data, not central registry data.

- Not randomised controlled trial.

- Limited documentation in medical charts of type of perineum support and type of episiotomy performed during second stage of delivery.

delivery with reported incidences varying from $1 \%$ to $6 \%,{ }^{1-5}$ and occurs even in otherwise uncomplicated deliveries. Obstetric anal sphincter injuries (OASIS) may cause pain, discomfort and anal incontinence $(\mathrm{AI}) .^{6-8}$

Risk factors for OASIS have been widely studied, with several hundred studies 
currently available in PubMed, assessing maternal, obstetric and foetal risk factors. Numerous factors have been investigated and focus has often been on factors that are not modifiable, such as maternal age, height, weight, ethnicity, foetal weight and head size. Most previous studies conclude that primiparity, large infant birth weight and instrumental delivery increase the risk of OASIS, but when exploring factors such as maternal age (young or advanced), ethnicity, epidural use and episiotomy, the results are conflicting. ${ }^{9-14}$ Risk factors unrelated to the delivering woman or the infant size, such as the accoucheurs' management of the second stage of delivery, have been less investigated.

The incidence of OASIS varies between countries and delivery units. $^{2-5} 15$ A steadily increasing incidence of OASIS has been reported in the Nordic countries over the last decades, ${ }^{2} 1516$ albeit still at a very low rate in Finland. ${ }^{2}$ Factors such as alterations in patient population over time (increasing maternal age, larger infants and increased use of instrumental delivery) have been studied, but such factors cannot alone explain the increasing incidence of OASIS. ${ }^{5} 15$

In 2004, the Norwegian National Board of Health criticised the delivery units for a high incidence of OASIS, at that time being $4.5 \%$ of vaginal deliveries, and required that hospitals should implement programmes to reduce the OASIS incidence. Programmes to introduce manual perineal protection in the second stage of delivery were implemented in many Norwegian hospitals, and a reduction in OASIS incidence was achieved. ${ }^{17}{ }^{18}$ In the Obstetric Department at Oslo University Hospital, Ullevål, attempts to reduce the incidence of OASIS were developed in steps, starting in 2006 with more focus on the OASIS issue in clinical meetings, whereas practical training to improve protection of perineum during the second stage of delivery started in 2008. Such training programmes have previously been described in two studies. ${ }^{17} 18$

The primary aim of the present study was to compare the incidence of OASIS across two time periods, before and after implementing a training programme for perineal protection during second stage of delivery, aimed at reducing the incidence of OASIS. A secondary aim was to study the incidence of OASIS in subgroups of women defined by risk factors.

\section{METHODS}

The study was conducted as a retrospective cohort study, in the largest delivery unit in Norway, at a university hospital with an unselected patient population in Oslo, with 7000 deliveries annually. Two cohorts from two time periods were studied, 2003-2005 and 2008-2010, before and after the intervention of a training programme for manual perineal protection during the second stage of delivery.

\section{Databases and participants}

Data were obtained from the hospital obstetric database, the electronic hospital discharge register, individual electronic and paper-based medical records, and from the manually assembled labour protocols at the delivery unit, during the time period from 2003 to 2010. Two cohorts were chosen to the study, 2003-2005 and 2008-2010.

Women with obstetric anal sphincter injuries were identified from the labour protocols at the delivery unit and validated against individual electronic and paperbased medical charts (by the first author: KL). Surgery notes for the perineum repair in the medical record for each case were carefully read, and false-positive cases were excluded $(n=22)$. In addition, patients with the diagnosis OASIS (ICD-10 code O70.2 or O70.3) were identified from the electronic hospital discharge register and 13 additional patients with OASIS were identified. After excluding women delivered with caesarean section, preterm deliveries (< week 32), triplets and quadruplets, the study population comprised 31709 deliveries, of which 907 women with OASIS.

\section{Definition and diagnostics of OASIS}

Obstetric anal sphincter injury was defined as any degree of injury in the anal sphincter muscle (3A, 3B, $3 \mathrm{C}$ and 4 th degree perineal tears, identified by the diagnoses O70.2 and O70.3 in the ICD-10 system). ${ }^{19}$

In Norway, spontaneous deliveries are attended by midwives whereas instrumental deliveries are handled by physicians. To increase safety during delivery for both the mother and the infant, the procedure at our department requires at least two accoucheurs (two midwives or one midwife and a physician) attending the second and third stage of each delivery. If the midwife suspects OASIS, a physician attends the labour room and evaluates and classifies the degree of perineal tear. The written procedure of the department is that a standardised surgical OASIS repair (end-to-end technique) is always performed under direct surveillance of an experienced obstetrician or gynaecologist (consultant).

\section{Risk factors for OASIS}

Information on maternal, obstetrical and foetal risk factors for OASIS was collected, including maternal age, parity, year of delivery, labour induction, delivery method, duration of second stage of labour, epidural use, episiotomy, persistent occiput posterior presentation, shoulder dystocia, infant birth weight and infant head circumference.

\section{The intervention programme}

The need to reduce the incidence of OASIS was discussed among delivery personnel in clinical meetings from 2006. An intervention programme was implemented from 2008, including both midwives and physicians at the Department of Obstetrics and Gynaecology. An external midwife was hired in from another hospital (where a similar programme was previously successfully implemented) to educate a group of trainer-midwives, who then further educated the entire midwife-staff. 
Physicians (both registrars and specialists) were educated in the perineal supporting technique and supervised by KL. First part of the training included a practical hands-on training on a pelvic delivery model and the second part included hands-on supervision in labour room during the second stage of delivery. The perineum protection programme consisted of four components during the last part of second stage of delivery, when the baby's head is crowning: slowing the delivery of the baby's head with one hand, supporting perineum with the other hand and squeezing with fingers (first and second) from the perineum lateral parts towards the middle in order to lower the pressure in middle posterior perineum, and asking the delivering woman not to push. The fourth part of the intervention was education in correct performing of episiotomy. At our department, episiotomy is performed only when indicated, for example due to foetal distress or imminent severe perineal tear. The main focus of this intervention step was to avoid median cuts of episiotomy technique, when performed, due to the augmented risk of OASIS associated with median episiotomies. ${ }^{20}$

\section{Comparison of groups}

The clinical characteristics of the study participants in the first (2003-2005) and second (2008-2010) time period were compared in order to identify possible population differences of delivering women between the two time periods (table 1 ).

\section{Statistical analysis}

Incidence of obstetric anal sphincter injuries was calculated from vaginal deliveries only and the data were stratified according to parity. Parity was adjusted to vaginal parity; women with one previous caesarean delivery only (never having delivered vaginally before) were categorised as 'vaginal primiparous' $(n=440)$.

The risk factors for OASIS were calculated and presented separately for the two cohorts. Continuous data were categorised and the independent variables are presented as frequencies. Univariate analysis was performed to explore the significant risk factors. Variables with $\mathrm{p} \leq 0.10$ were included in the multivariate analysis. Univariate analyses were performed by $\chi^{2}$ test. A significance level of $5 \%$ was chosen in all analyses. Adjusted ORs (aORs) for OASIS with 95\% CI are reported from multivariate logistic regression analyses. The data were analysed by using PASW (Predictive Analytics SoftWare, SPSS Inc, V.19.0, Chicago, Illinois, USA).

\section{RESULTS}

Overall incidence of anal sphincter injury in vaginal deliveries was significantly reduced by $50 \%$, from $4 \%$

\begin{tabular}{|c|c|c|c|c|}
\hline \multirow[b]{2}{*}{ Time period } & \multicolumn{2}{|c|}{ Primiparous women } & \multicolumn{2}{|c|}{ Multiparous women } \\
\hline & 2003-2005 & 2008-2010 & 2003-2005 & 2008-2010 \\
\hline $\mathrm{n}$ vaginal deliveries & $\mathrm{n}=8051$ & $\mathrm{n}=8837$ & $n=6736$ & $\mathrm{n}=8085$ \\
\hline \multicolumn{5}{|l|}{ Risk factors } \\
\hline Age (years) & $p<0.001$ & & $\mathrm{p}<0.001$ & \\
\hline $15-29$ & $48.3(n=3885)$ & $43.8(n=3872)$ & $27.4(n=1849)$ & $21.4(n=1730)$ \\
\hline $30-34$ & $39.3(n=3164)$ & $40.8(n=3604)$ & $42(n=2823)$ & $40.7(n=3287)$ \\
\hline $35-51$ & $12.4(n=1002)$ & $15.4(n=1361)$ & $30.6(n=2064)$ & $37.9(n=3068)$ \\
\hline Birthweight (g) & $\mathrm{p}=0.003$ & & $\mathrm{p}=0.60$ & \\
\hline 720-2999 & $16.4(n=1321)$ & $16.4(n=1446)$ & $11.8(n=794)$ & $11.6(n=938)$ \\
\hline 3000-3499 & $37.9(n=3050)$ & $39.2(n=3470)$ & $32.5(n=2191)$ & $32(\mathrm{n}=2591)$ \\
\hline 3500-3999 & $33.2(n=2670)$ & $33.8(n=2983)$ & $36.3(n=2447)$ & $37.5(n=3029)$ \\
\hline 4000-4499 & $11(n=885)$ & $9.3(n=821)$ & $15.6(n=1049)$ & $15.4(n=1247)$ \\
\hline $4500-5850$ & $1.5(n=125)$ & $1.3(n=117)$ & $3.8(n=255)$ & $3.5(n=280)$ \\
\hline Delivery method & $\mathrm{p}<0.001$ & & $\mathrm{p}=0.45$ & \\
\hline Spontaneous & $81.5(n=6558)$ & $78.3(n=6918)$ & $96.2(n=6479)$ & $96.4(n=7793)$ \\
\hline Ventouse & $16.5(n=1331)$ & $20.4(n=1802)$ & $3.5(n=234)$ & $3.4(n=273)$ \\
\hline Forceps & $2(n=162)$ & $1.3(n=117)$ & $0.3(n=23)$ & $0.2(n=19)$ \\
\hline \multirow{2}{*}{ Episiotomy, all vaginal deliveries } & $p<0.001$ & & $\mathrm{p}=0.066$ & \\
\hline & $31.4(n=2528)$ & $36.2(n=3203)$ & $7.3(n=492)$ & $8.1(n=656)$ \\
\hline \multirow[t]{2}{*}{ Episiotomy, spontaneous deliveries } & $\mathrm{p}=0.006$ & & $\mathrm{p}=0.98$ & \\
\hline & $24.7(n=1620)$ & $22.7(n=1569)$ & $6.1(n=396)$ & $6.1(n=477)$ \\
\hline \multirow[t]{2}{*}{ Episiotomy, instrumental deliveries } & $p<0.001$ & & $p<0.001$ & \\
\hline & $60.8(n=908)$ & $85.1(n=1634)$ & $37.4(n=96)$ & $61.3(n=179)$ \\
\hline Duration second stage ( $\mathrm{min}$ ) & $\mathrm{p}=0.057$ & & $p=0.45$ & \\
\hline $0-29$ & $34.1(n=2736)$ & $32.5(n=2864)$ & $84.9(n=5696)$ & $85.4(n=6895)$ \\
\hline $30-59$ & $41(n=3290)$ & $41.6(n=3673)$ & $12.5(n=839)$ & $11.9(n=957)$ \\
\hline $60-205$ & $24.9(n=1994)$ & $25.9(n=2288)$ & $2.6(n=174)$ & $2.7(n=219)$ \\
\hline
\end{tabular}


$(591 / 14787)$ in the first time period (2003-2005) to $1.9 \%(316 / 16922)$ in the second time period (200810). The reduction of the incidence of OASIS was of similar magnitude across all studied subgroups defined by risk factors, for both primiparous and multiparous women (table 2).

The incidence of OASIS over the study years is displayed in figure 1, demonstrating a reduced incidence of OASIS, which in time follows the implementation of the perineum support programme for the staff.
Figure 1 also demonstrates a similar reduction of OASIS incidence for the different delivery methods (operative and spontaneous vaginal delivery) between the two study periods: in spontaneous deliveries the OASIS incidence was reduced from 3.1\% (409/13 037) to $1.5 \%(215 / 14711)$ and in ventouse from $9.7 \%$ (152/ $1565)$ to $4.7 \%(98 / 2075)$. Forceps is less used in our department, but a significant OASIS reduction was also observed in forceps deliveries from $16.2 \%(30 / 185)$ to $2.2 \%(3 / 136)$.

Table 2 Incidence of OASIS in different subgroups of women. Data are presented in frequencies (and numbers). $p$ Values from $\chi^{2}$ test

\begin{tabular}{|c|c|c|c|c|c|c|}
\hline \multirow[b]{2}{*}{ Time period } & \multicolumn{2}{|c|}{ Primiparous women } & & \multicolumn{2}{|c|}{ Multiparous women } & \\
\hline & 2003-2005 & 2008-2010 & & 2003-2005 & 2008-2010 & \\
\hline OASIS & $6.1(489 / 8051)$ & $3(263 / 8837)$ & & $1.5(102 / 6736)$ & $0.7(53 / 8085)$ & \\
\hline \multicolumn{7}{|l|}{ Risk factors } \\
\hline Age (years) & & & $P$ & & & $P$ \\
\hline $15-29$ & $5.5(212 / 3885)$ & $2.8(107 / 3872)$ & $<0.001$ & $1.4(25 / 1849)$ & $0.5(9 / 1730)$ & 0.01 \\
\hline $30-34$ & $6.7(212 / 3164)$ & $3.3(118 / 3604)$ & $<0.001$ & $1.6(45 / 2823)$ & $0.7(22 / 3287)$ & 0.001 \\
\hline $35-51$ & $6.5(65 / 1002)$ & $2.8(38 / 1361)$ & $<0.001$ & $1.6(32 / 2064)$ & $0.7(22 / 3068)$ & 0.004 \\
\hline \multicolumn{7}{|l|}{ Birthweight (g) } \\
\hline $720-2999$ & $3(39 / 1321)$ & $1.6(23 / 1446))$ & 0.016 & $0.4(3 / 794)$ & $0.5(5 / 938)$ & 0.63 \\
\hline 3000-3499 & $4.4(135 / 3050)$ & $2.6(90 / 3470)$ & $<0.001$ & $0.8(18 / 2191)$ & $0.4(10 / 2591)$ & 0.049 \\
\hline 3500-3999 & $7.2(192 / 2670)$ & $3.4(101 / 2983)$ & $<0.001$ & $1.3(33 / 2447)$ & $0.6(19 / 3029)$ & 0.006 \\
\hline 4000-4499 & $11.2(99 / 885)$ & $4.8(39 / 821)$ & $<0.001$ & $3.2(34 / 1049)$ & $0.7(9 / 1247)$ & $<0.001$ \\
\hline $4500-5850$ & $19.2(24 / 125)$ & $8.5(10 / 117)$ & 0.017 & $5.5(14 / 255)$ & $3.6(10 / 280)$ & 0.28 \\
\hline \multicolumn{7}{|l|}{ Delivery method } \\
\hline Spontaneous & $4.8(318 / 6558)$ & $2.5(170 / 6918)$ & $<0.001$ & $1.4(91 / 6479)$ & $0.6(45 / 7793)$ & $<0.001$ \\
\hline Ventouse & $10.8(144 / 1331)$ & $5(90 / 1802)$ & $<0.001$ & $3.4(8 / 234)$ & $2.9(8 / 273)$ & 0.75 \\
\hline Forceps & $16.7(27 / 162)$ & $2.6(3 / 117)$ & $<0.001$ & $13(3 / 23)$ & $0(0 / 19)$ & 0.10 \\
\hline \multicolumn{7}{|c|}{ Episiotomy, all deliveries } \\
\hline Yes & $6.6(166 / 2528)$ & $3(96 / 3203)$ & $<0.001$ & $2(10 / 492)$ & $1.8(12 / 656)$ & 0.80 \\
\hline No & $5.8(323 / 5523)$ & $3(167 / 5634)$ & $<0.001$ & $1.5(92 / 6244)$ & $0.6(41 / 7429)$ & $<0.001$ \\
\hline \multicolumn{7}{|c|}{ Episiotomy, spontaneous deliveries } \\
\hline Yes & $4(65 / 1620)$ & $2.2(34 / 1569)$ & $<0.003$ & $1.3(5 / 396)$ & $1.3(6 / 477)$ & 1 \\
\hline No & $5.1(253 / 4938)$ & $2.5(136 / 5349)$ & $<0.001$ & $1.4(86 / 6083)$ & $0.5(39 / 7316)$ & $<0.001$ \\
\hline \multicolumn{7}{|c|}{ Episiotomy, instrumental deliveries } \\
\hline Yes & $11.1(101 / 908)$ & $3.8(62 / 1634)$ & $<0.001$ & $5.2(5 / 96)$ & $3.4(6 / 179)$ & 0.45 \\
\hline No & $12(70 / 585)$ & $10.9(31 / 285)$ & 0.64 & $3.7(6 / 161)$ & $1.8(2 / 113)$ & 0.34 \\
\hline \multicolumn{7}{|c|}{ Duration second stage (min) } \\
\hline 0-09 & $4.6(13 / 281)$ & $3.3(9 / 273)$ & 0.42 & $0.9(20 / 2335)$ & $0.4(10 / 2390)$ & 0.058 \\
\hline $10-29$ & $4(99 / 2455)$ & $2.9(74 / 2591)$ & 0.02 & $1.5(50 / 3361)$ & $0.5(21 / 4505)$ & $<0.001$ \\
\hline $30-59$ & $5.5(180 / 3290)$ & $2.5(93 / 3673)$ & $<0.001$ & $2.9(24 / 839)$ & $1.7(16 / 957)$ & 0.09 \\
\hline 60-205 & $9.7(193 / 1994)$ & $3.8(87 / 2288)$ & $<0.001$ & $4(7 / 174)$ & $2.3(5 / 219)$ & 0.32 \\
\hline \multicolumn{7}{|l|}{ Epidural } \\
\hline Yes & $6.5(228 / 3494)$ & $3(128 / 4267)$ & $<0.001$ & $2(20 / 1008)$ & $0.8(12 / 1419)$ & 0.015 \\
\hline No & $5.7(261 / 4557)$ & $3(135 / 4570)$ & $<0.001$ & $1.4(82 / 5728)$ & $0.6(41 / 6666)$ & $<0.001$ \\
\hline \multicolumn{7}{|c|}{ Shoulder dystocia } \\
\hline Yes & $15.8(12 / 76))$ & $14.1(9 / 64)$ & 0.78 & $5.7(5 / 87)$ & $4.1(3 / 73)$ & 0.64 \\
\hline No & $6(477 / 7975)$ & $2.9(254 / 8773)$ & $<0.001$ & $1.5(97 / 6649)$ & $0.6(50 / 8012)$ & $<0.001$ \\
\hline \multicolumn{7}{|c|}{ Occiput posterior presentation } \\
\hline Yes & $11.4(20 / 176)$ & $6.9(17 / 245)$ & 0.11 & $0.7(1 / 150)$ & $1.7(4 / 237)$ & 0.39 \\
\hline No & $6(469 / 7875)$ & $2.9(246 / 8592)$ & $<0.001$ & $1.5(101 / 6586)$ & $0.6(49 / 7848)$ & $<0.001$ \\
\hline \multicolumn{7}{|l|}{ Induced labour } \\
\hline Yes & $5.5(75 / 1365)$ & $3(50 / 1650)$ & 0.001 & $1.3(12 / 903)$ & $0.7(9 / 1269)$ & 0.18 \\
\hline No & $6.2(414 / 6686)$ & $3(213 / 7187)$ & $<0.001$ & $1.5(90 / 5833)$ & $0.6(44 / 6816)$ & $<0.001$ \\
\hline
\end{tabular}




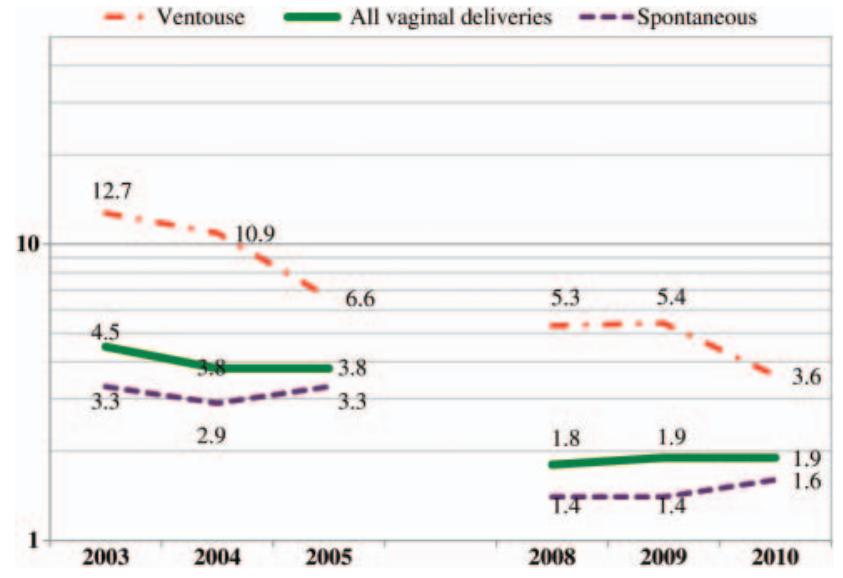

Figure 1 Frequency of obstetric anal sphincter injuries (\%) for different delivery methods during the study years.

\section{Population characteristics across the study years}

Overall changes in population characteristics between the two time periods were small, but the prevalence of older women ( $>35$ years) was significantly higher in the second period (2008-10), and use of ventouse delivery, episiotomy, epidural and induction of labour was more frequent (table 1). Primiparous women comprised $85 \%$ of the women with OASIS, but represented only 53.3\% of the overall study population.

\section{Primiparous women}

In a univariate analysis, higher infant birth weight, larger infant head circumference (data not shown), prolonged second stage of labour, instrumental delivery, shoulder dystocia and persistent occiput posterior presentation were significant OASIS risk factors for primiparous women in the first study period (table 3). In the second study period, the same OASIS risk factors remained significant, except for a prolonged second stage of labour (table 3).

Looking at the various explanatory variables (such as age, maternal body mass index, foetal weight, etc) and analysing time period solely as an explanatory variable for OASIS (due to the perineal protection programme introduced in the second time period), we observed that the first time period emerged as one of the most important 'risk factors' with high OR for OASIS in our study. Without adjusting for any other variables, OR for OASIS in the logistic regression analysis for the first study period as compared with the second was 2.10 (95\% CI 1.76 to 2.40$)$.

In a multivariate regression analysis (table 4), large infant birth weight, instrumental delivery, prolonged second stage and occiput posterior presentation were significant risk factors for OASIS in the first study period. In the second study period, when the incidence of OASIS was reduced, only instrumental delivery and foetal occiput posterior presentation remained significant risk factors for OASIS.
Frequency of episiotomy use in spontaneous deliveries of primiparous women was reduced from the first time period to the second, and increased in instrumental deliveries (table 1). When adjusted for risk factors in the multivariate analysis, episiotomy appeared as a protective factor for OASIS in both time periods for primiparous women (table 4).

Primiparous women with a previous caesarean section only, and no previous vaginal delivery $(n=440)$, had an increased OASIS risk compared to women with no previous delivery $\mathrm{OR}=2.2$ (95\% CI 1.6 to 3.1), both in the first time period $(11.5 \%$ and $5.9 \%$, respectively, $P=0.001)$ and in the second $(6.7 \%$ and $2.9 \%$, respectively, $P=0.001)$. Also in this subgroup, the OASIS incidence was reduced with $50 \%$ after implementation of the perineal protection programme. When the various study analyses were performed without this small subgroup of vaginal primiparous women with one previous caesarean only, the study conclusions remained unaltered, as expected due to the small number of women in this subgroup.

\section{Multiparous women}

In a univariate analysis for multiparous women (table 5), instrumental delivery, prolonged second stage of delivery, shoulder dystocia, large infant head circumference (data not shown) and birth weight were significant risk factors for OASIS in both time periods. The risk of OASIS was markedly reduced from the first to the second time period and the time period for the delivery was one of the most important 'risk factors'; OR for OASIS in the logistic regression analysis for the first time period as compared with the second was $2.31(95 \%$ CI 1.65 to 3.25$)$.

In the multivariate regression analysis (table 4), macrosomia and instrumental delivery significantly increased the OASIS risk for multiparous women in the first time period, but not in the second. In the second time period, none of the identified risk factors for OASIS were significant for multiparous women. However, OASIS cases were few $(n=53)$ in this subgroup of women. In the multivariate analysis the effect of episiotomy was non-significant in both time periods (table 4). However, multiparous women with episiotomy were very few in this study and interpretation of the results should be undertaken cautiously (tables 2 and 5).

\section{DISCUSSION}

In this study, comprising 31709 vaginal deliveries, the OASIS incidence was reduced by $50 \%$ after introduction of a training programme on perineal protection during the second stage of delivery, aimed at reducing incidence of OASIS. The reduction in the OASIS incidence was similar in all subgroups defined by OASIS risk factors.

Similar reduction in OASIS following alteration in clinical routines and intervention programmes during the second stage of delivery have been presented 
Table 3 Clinical characteristics and obstetric interventions among primiparous women with OASIS and women without OASIS. Data are presented in frequencies (and numbers). $p$ Values from $\chi^{2}$ test

\begin{tabular}{|c|c|c|c|c|}
\hline \multirow[b]{2}{*}{ Primiparous women } & \multicolumn{2}{|l|}{ 2003-2005 } & \multicolumn{2}{|l|}{ 2008-2010 } \\
\hline & OASIS & Non-OASIS & OASIS & Non-OASIS \\
\hline Deliveries & $n=489$ & $n=7562$ & $n=263$ & $n=8574$ \\
\hline Incidence OASIS & $6.1(489 / 7562)$ & & $3(263 / 8574)$ & \\
\hline \multicolumn{5}{|l|}{ Risk factors (\%) } \\
\hline Age (years) & $p=0.08$ & & $p=0.39$ & \\
\hline $15-29$ & $43.4(n=212)$ & $48.6(n=3673)$ & $40.7(n=107)$ & $43.9(n=3765)$ \\
\hline 30-34 & $43.4(n=212)$ & $39(n=2952)$ & $44.9(n=118)$ & $40.7(n=3486)$ \\
\hline $35-51$ & $13.3(n=65)$ & $12.4(n=937)$ & $14.4(n=38)$ & $15.4(n=1323)$ \\
\hline Birthweight (g) & $p<0.001$ & & $\mathrm{p}<0.001$ & \\
\hline $720-2999$ & $8(n=39)$ & $17(n=1282)$ & $8.7(n=23)$ & $16.6(n=1423)$ \\
\hline 3000-3499 & $27.6(n=135)$ & $38.5(n=2915)$ & $34.2(n=90)$ & $39.4(n=3380)$ \\
\hline 3500-3999 & $39.3(n=192)$ & $32.8(n=2478)$ & $38.4(n=101)$ & $33.6(n=2882)$ \\
\hline $4000-4499$ & $20.2(n=99)$ & $10.4(n=786)$ & $14.8(n=39)$ & $9.1(n=782)$ \\
\hline 4500-5850 & $4.9(n=24)$ & $1.3(n=101)$ & $3.8(n=10)$ & $1.2(n=107)$ \\
\hline Delivery method & $p<0.001$ & & $p<0.001$ & \\
\hline Spontaneous & $65(n=318)$ & $82.5(n=6240)$ & $64.6(n=170)$ & $78.7(n=6748)$ \\
\hline Ventouse & $29.4(n=144)$ & $15.7(n=1187)$ & $34.2(n=90)$ & $20(n=1712)$ \\
\hline Forceps & $5.5(n=27)$ & $1.8(n=135)$ & $1.1(n=3)$ & $1.3(n=114)$ \\
\hline \multirow[t]{2}{*}{ Episiotomy, all vaginal deliveries } & $p=0.21$ & & $p=0.93$ & \\
\hline & $33.9(n=166)$ & $31.2(n=2362)$ & $36.5(n=96)$ & $36.2(n=3107)$ \\
\hline \multirow[t]{2}{*}{ Episiotomy, spontaneous deliveries } & $p=0.07$ & & $p=0.40$ & \\
\hline & $20.4(n=65)$ & $24.9(n=1555)$ & $20(n=34)$ & $22.7(n=1535)$ \\
\hline \multirow[t]{2}{*}{ Episiotomy, instrumental deliveries } & $p<0.001$ & $\mathrm{p}<0.001$ & & \\
\hline & $59.1(n=101)$ & $61(n=807)$ & $66.7(n=62)$ & $86.1(n=1572)$ \\
\hline Duration second stage (min) & $p<0.001$ & & $p=0.07$ & \\
\hline 0-09 & $2.7(n=13)$ & $3.5(n=268)$ & $3.4(n=9)$ & $3.1(n=264)$ \\
\hline 10-29 & $20.2(n=99)$ & $31.2(n=2356)$ & $28.1(n=74)$ & $29.4(n=2517)$ \\
\hline $30-59$ & $36.8(n=180)$ & $41.1(n=3110)$ & $35.4(n=93)$ & $41.8(n=3580)$ \\
\hline 60-205 & $39.5(n=193)$ & $23.8(n=1801)$ & $33.1(n=87)$ & $25.7(n=2201)$ \\
\hline Missing data $(n=4 / n=27)$ & $0.8(n=4)$ & $0.4(n=27)$ & $0(n=0)$ & $0.1(n=12)$ \\
\hline \multirow[t]{2}{*}{ Epidural } & $p=0.14$ & & $p=0.90$ & \\
\hline & $46.6(n=228)$ & $43.2(n=3266)$ & $48.7(n=128)$ & $48.3(n=4139)$ \\
\hline \multirow[t]{2}{*}{ Shoulder dystocia } & $p<0.001$ & & $p<0.001$ & \\
\hline & $2.5(n=12)$ & $0.8(n=64)$ & $3.4(n=9)$ & $0.6(n=55)$ \\
\hline \multirow[t]{2}{*}{ Occiput posterior presentation } & $p=0.003$ & & $p<0.001$ & \\
\hline & $4.1(n=20)$ & $2.1(n=156)$ & $6.5(n=17)$ & $2.7(n=228)$ \\
\hline \multirow[t]{2}{*}{ Induced labour } & $p=0.32$ & & $p=0.89$ & \\
\hline & $15.3(n=75)$ & $17.1(n=1290)$ & $19(n=50)$ & $18.7(n=18.7)$ \\
\hline
\end{tabular}

previously, both in Norway, ${ }^{17} 18$ and in the USA, ${ }^{21}$ but we are not aware of other publications exploring the reduced incidence of OASIS in different subgroups defined by risk factors.

\section{Strengths and limitations of the study}

Strengths of this hospital-based large observational study includes a very low risk of diagnostic misclassification of the OASIS outcome as all OASIS diagnoses were validated for study purposes in addition to primarily being diagnosed by at least two accoucheurs, and always by an obstetrician or gynaecologist. This is in contrast to studies based on registries that are not primarily created for research, but are established for other purposes for the healthcare providers. In our study, the medical records of all patients registered with an OASIS were carefully reviewed by one senior consultant (KL). In addition, diagnosis of OASIS cases were cross-checked between several available sources (individual patient records, delivery unit protocols and hospital discharge lists, including ICD-10 diagnose codes and surgical codes for OASIS repair) for the study years. Another strength is that the study was carried out at in a single large hospital focusing on improved quality of primary diagnosis and repair of OASIS, and this also reduces the risk of misclassification in registration. Strength of the study is also the unselected population of delivering women and a large number of deliveries.

A randomised controlled trial (RCT) would be the optimal design for evaluating an OASIS reducing effect of manual perineum protection, but carrying out such an RCT is challenging during delivery, due to 
Table 4 Risk factors for OASIS in the multivariate regression model (adjusted OR(aOR) and 95\% Cl)

\begin{tabular}{|c|c|c|c|c|}
\hline \multirow[b]{2}{*}{ Time period } & \multicolumn{2}{|l|}{ Primiparous women } & \multicolumn{2}{|l|}{ Multiparous women } \\
\hline & $2003-05$ & 2008-10 & $2003-05$ & 2008-10 \\
\hline Vaginal deliveries & $n=8051$ & $\mathrm{n}=8837$ & $n=6736$ & $n=8085$ \\
\hline OASIS (n) & 489 & 263 & 102 & 53 \\
\hline Incidence OASIS (\%) & 6 & 3 & 1.5 & 0.7 \\
\hline Risk factors & aOR $(95 \% \mathrm{Cl})$ & aOR $(95 \% \mathrm{Cl})$ & aOR $(95 \% \mathrm{Cl})$ & aOR $(95 \% \mathrm{Cl})$ \\
\hline \multicolumn{5}{|l|}{ Age (years) } \\
\hline $15-29$ & $0.90(0.72$ to 1.08$)$ & $0.90(0.67$ to 1.15$)$ & 0.99 (0.60 to 1.64$)$ & $0.86(0.40$ to 1.90$)$ \\
\hline $30-34$ & 1 & 1 & 1 & 1 \\
\hline $35-51$ & $0.96(0.71$ to 1.28$)$ & 0.84 (0.58 to 1.22$)$ & 0.91 (0.57 to 1.44$)$ & $0.95(0.52$ to 1.75$)$ \\
\hline \multicolumn{5}{|l|}{ Birthweight (g) } \\
\hline 720-3499 & $0.70(0.55$ to 0.87$)$ & $0.80(0.60$ to 1.08$)$ & $0.46(0.25$ to 0.82$)$ & $0.93(0.44$ to 1.94$)$ \\
\hline 3500-3999 & 1 & 1 & 1 & 1 \\
\hline $4000-5850$ & 1.50 (1.16 to 1.92$)$ & 1.26 (0.87 to 1.83$)$ & 2.81 (1.73 to 4.58$)$ & 1.19 (0.58 to 2.45$)$ \\
\hline \multicolumn{5}{|l|}{ Delivery method } \\
\hline Spontaneous & 1 & 1 & 1 & 1 \\
\hline Instrumental & 2.10 (1.71 to 2.68$)$ & 2.46 (1.74 to 3.47$)$ & 2.19 (1.02 to 4.73$)$ & 1.72 (0.64 to 4.66$)$ \\
\hline \multicolumn{5}{|l|}{ Episiotomy } \\
\hline No & 1 & 1 & 1 & 1 \\
\hline Yes & $0.72(0.58$ to 0.90$)$ & 0.52 (0.38 to 0.73$)$ & 0.92 (0.46 to 1.87$)$ & 1.57 (0.71 to 3.49$)$ \\
\hline \multicolumn{5}{|c|}{ Duration second stage $(\min )$} \\
\hline 0-29 & $0.80(0.62$ to 1.02$)$ & $1.18(0.87$ to 1.60$)$ & 0.50 (0.31 to 0.82$)$ & $0.34(0.18$ to 0.64$)$ \\
\hline $30-59$ & 1 & 1 & 1 & 1 \\
\hline 60-205 & $1.40(1.15$ to 1.79$)$ & $1.29(0.95$ to 1.75$)$ & $1.03(0.41$ to 2.58$)$ & $0.83(0.28$ to 2.48$)$ \\
\hline \multicolumn{5}{|l|}{ Epidural } \\
\hline No & 1 & 1 & 1 & 1 \\
\hline Yes & $0.95(0.78$ to 1.15$)$ & $0.86(0.67$ to 1.12$)$ & 1.15 (0.69 to 1.93$)$ & $0.88(0.44$ to 1.76$)$ \\
\hline \multicolumn{5}{|l|}{ Shoulder dystocia } \\
\hline No & 1 & 1 & 1 & 1 \\
\hline Yes & $1.58(0.83$ to 1.39$)$ & $3.73(1.76$ to 7.90$)$ & $1.58(0.60$ to 4.16$)$ & $2.25(0.50$ to 10.10$)$ \\
\hline \multicolumn{5}{|c|}{ Occiput posterior presentation } \\
\hline No & 1 & 1 & 1 & 1 \\
\hline Yes & 1.72 (1.04 to 2.82 ) & 2.40 (1.42 to 4.06$)$ & 0.24 (0.03 to 1.78$)$ & 1.95 (0.66 to 5.73$)$ \\
\hline \multicolumn{5}{|l|}{ Induced labour } \\
\hline No & 1 & 1 & 1 & 1 \\
\hline Yes & $0.77(0.60$ to 1$)$ & 0.92 (0.66 to 1.27$)$ & $0.86(0.46$ to 1.60$)$ & 0.81 (0.37 to 1.77$)$ \\
\hline
\end{tabular}

contamination of methods in different study arms and problems with blinding of patients or staff. We did not conduct an RCT because in Norway, several hospitals already had managed to reduce the incidence of OASIS with implementation of improved manual perineal protection, and we consider randomising women to handsoff delivering techniques as unethical in the light of these recent historical clinical results. Previous RCTs have not shown a beneficial effect on OASIS by hands-on perineal protection, but the published RCTs have not described a structured training of the staff, such as the intervention programme of our study. ${ }^{22}$ These trials had problems with bias caused by contamination of compared methods and different use of medial episiotomy in the study arms, ${ }^{23} 24$ were under-powered to explore OASIS, or were not designed to assess OASIS, but perineal pain or perineal injury in general (including first and second degree tears and episiotomy). ${ }^{23-25}$ The marked $50 \%$ reduction in the OASIS incidence obtained in our delivery unit appeared simultaneously with the introduction of a manual perineal protection during second stage of labour. The main difference for our study population between the two time periods was the perineum protection training programme, the patient characteristics remained almost unaltered between the time periods and could not explain the reduction of incidence of OASIS. Thus, our study indicates that such a perineal protection programme has a beneficial effect in reducing the incidence of OASIS, both for primiparous and multiparous women, despite the lack of an RCT supporting this conclusion.

A weakness of our study is that the use of perineum support method, if used during second stage of delivery, was not registered in the medical records, and therefore, use of perineum support could not be assessed directly in our retrospective study. However, if this method was not used in some deliveries during the second time period or was used in some deliveries during the first 
Table 5 Clinical characteristics and obstetric interventions among multiparous women with OASIS and women without OASIS. Data are presented in frequencies (and numbers). $p$-Values from $\chi^{2}$ test

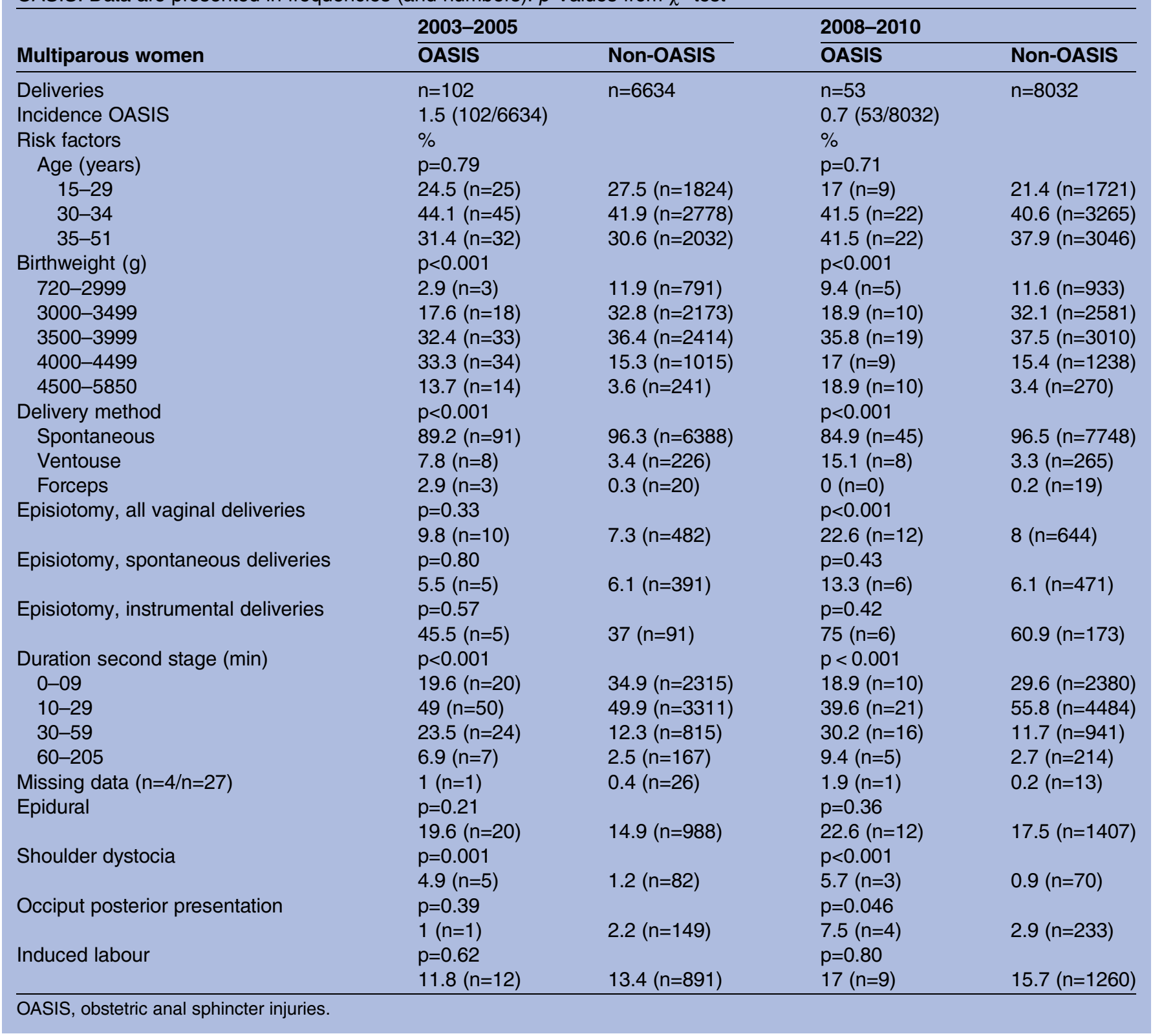

time period, our study would tend to underestimate the OASIS incidence reducing effect of the perineum protection intervention programme, and hence, our efficacy estimates on reduction of OASIS from the intervention are minimum estimates.

\section{Meaning of the study}

The observed reduction of incidence of OASIS came rapidly after the introduction of the perineal protection programme and the low incidence of OASIS has lasted over the last years. The changes in clinical characteristics of the study population were very modest between the two time periods, and cannot explain the rapid reduction of the incidence of OASIS. Without the intervention programme, we could have expected an increase of the incidence of OASIS in the second time period, as one of the most important OASIS risk factors, instrumental delivery, became more frequent in the study population (table 1) over the study years. In our study the reduction of incidence of OASIS was surprisingly consistent in all subgroups defined by OASIS risk factors (table 2). The decrease of the incidence of OASIS was similar in spontaneous and operative deliveries and in parity groups (primiparous and multiparous), again surprising, as primiparity is one of the most important risk factors for OASIS, as is operative delivery. ${ }^{5} 10^{15}$ Interestingly, as shown in figure 1, the 2010 incidence of OASIS in women delivered by ventouse delivery is of similar magnitude as the incidence of OASIS in the spontaneous deliveries was back in 2005 (3.6\% and 3.8\%, respectively). 
Under-reporting OASIS cases in the second time period is an unlikely cause for the registered reduction of the incidence of OASIS, as the procedure emphasising more than one accoucheur present at all deliveries was introduced before the second study period in form of a written procedure. Caesarean rate was unaltered between the two study periods and cannot explain the reduction of the incidence of OASIS.

\section{Comparison with other studies}

Traditionally, there has been a focus on OASIS risk factors with high OR. However, such risk factors may not necessarily represent the most frequent events in a delivery unit. Shoulder dystocia and occiput posterior presentation are examples of risk factors with high OR and a very low incidence. ${ }^{5}{ }^{15}$ In numbers, most of the OASIS occurs during deliveries with low risk; during spontaneous deliveries with an infant of normal size. In our study, the number of women with OASIS illustrates the major groups of women that will suffer this obstetric complication; of the 752 primiparous women with OASIS in our study, 488 delivered spontaneously, only 21 after shoulder dystocia, 39 from an infant in occiput posterior presentation. In total $77 \%(580 / 752)$ of the primiparous women with OASIS delivered an infant that was not macrosomic ( $>4000 \mathrm{~g}$ ). Actually, $38 \%$ of the women with OASIS delivered an infant smaller than the mean infant birth weight $(3500 \mathrm{~g})$ in our study population.

Medial and close to medial episiotomies have a higher risk for OASIS. ${ }^{20}$ Large register studies show that mediolateral and lateral episiotomies have a protecting effect against OASIS, particularly among primiparous women and in instrumental deliveries. ${ }^{9}{ }^{10}{ }^{26-28}$ Use of episiotomy was registered in our study, but type of episiotomy was not registered, and improvement of performed episiotomy technique in order to avoid median cuts was a part of the training package at our delivery unit.

During the study period, the use of episiotomy in our hospital decreased slightly in spontaneous deliveries in primiparous women (from $24.7 \%$ to $22.7 \%$ ), but increased in instrumental deliveries in primiparous women (from $60.8 \%$ to $85.1 \%$; table 1), and was shown to be a protective factor against OASIS for primiparous women in both time periods (table 4). Differences in effect of episiotomy between different parity groups on OASIS occurrence can be explained by indication bias, a mix between cause and effect, as episiotomy is used in deliveries with high OASIS risk. Multiparous women needing episiotomy may represent a group of women with difficult delivery with many risk factors.

\section{Research and policy implications}

We expected a more notable reduction of the incidences of OASIS in the subgroups with lower risk (low or normal infant birth weight), as compared with women with higher risk (large infant), if the perineal support programme had been followed consistently in all deliveries. We believe that a non-consistent use of perineum support in deliveries with lower risk for OASIS could account for the results; the main clinical focus was on women with high risk for OASIS, based on publications focusing on such risk factors. Previous studies have shown that antenatal scoring systems based on patient risk factors could not predict OASIS, ${ }^{29-31}$ therefore methods that reduce risk for OASIS should be offered to all delivering women, not only for women in high risk for OASIS.

The training programme for perineal protection is a low-cost intervention requiring no extra resources or equipment, only training of the existing staff. Such perineum protection programmes were previously successfully implemented in five hospitals in Norway, ${ }^{17}{ }^{18}$ therefore we can conclude that the programme is easily generalisable and applicable to other settings than ours.

\section{CONCLUSIONS}

Our study shows a large and rapid reduction of the incidence of OASIS following an introduction of a perineum support programme, across all risk groups of OASIS. We suggest that future OASIS research should focus more on variables connected to delivery procedures, including perineal protection procedures during delivery and not restricting risk analyses to demographic and individual obstetric data of the delivering woman or the infant. Using manual perineal protection is a low-cost intervention and requires no extra resources or equipment, except for training of the existing personnel. The reduction of incidence of OASIS in the last time period of our study could not be explained by the differences in patient characteristics or risk factors across the study period, because the incidence of these risk factors in the two time periods were either the same or increased in the second time period. Our study indicates that training programme for improved perineal protection can reduce the risk of OASIS across all groups of delivering women, not only in high-risk groups.

\section{Author affiliations}

${ }^{1}$ Department of Obstetrics, Oslo University Hospital, Ullevål, Oslo, Norway

${ }^{2}$ Faculty of Medicine, University of Oslo, Oslo, Norway

${ }^{3}$ Women's Health and Perinatology Research Group, Department of Clinical Medicine, University of Tromsø, Tromsø, Norway

${ }^{4}$ Unit of Biostatistics and Epidemiology, Oslo University Hospital, Oslo, Norway

${ }^{5}$ Department of Gynaecology, Oslo University Hospital, Ullevål, Oslo, Norway

Contributors All the authors' contributed to create the manuscript. KL had the study idea, initiated the study, planned the study, performed data retrieval from hospital systems and records, performed all data analyses, wrote first draft of manuscript, prepared the manuscript and submitted the last version. FES participated in study planning, data analysis and manuscript preparation and accepted last manuscript that was submitted. LS participated in data analysis and manuscript preparation and accepted last manuscript that was submitted. ACS supervised the planning of the study and all data analyses and contributed to writing first draft of manuscript, revised the manuscript and accepted last manuscript that was submitted. PhD supervisor of KL.

Data sharing statement No additional data are available. 
Funding This research received no funding.

Competing interests None

Provenance and peer review Not commissioned; internally peer reviewed.

\section{REFERENCES}

1. Räisänen $\mathrm{S}$, Vehviläinen-Julkunen $\mathrm{K}$, Gissler $\mathrm{M}$, et al. Up to seven-fold inter-hospital differences in obstetric anal sphincter injury rates - a birth register-based study in Finland. BMC Res Notes 2010;3:345.

2. Laine K, Gissler M, Pirhonen J. Changing incidence of anal sphincter tears in four Nordic countries through the last decades. Eur J Obstet Gynecol Reprod Biol 2009;146:71-5.

3. Pirhonen JP, Grenman SE, Haadem K, et al. Frequency of anal sphincter rupture at delivery in Sweden and Finland-result of difference in manual help to the baby's head. Acta Obstet Gynecol Scand 1998;77:974-7.

4. Prager M, Andersson KL, Stephansson O, et al. The incidence of obstetric anal sphincter rupture in primiparous women: a comparison between two European delivery settings. Acta Obstet Gynecol Scand 2008;87:209-15.

5. Baghestan E, Irgens LM, Bordahl PE, et al. Trends in risk factors for obstetric anal sphincter injuries in Norway. Obstet Gynecol 2010;116:25-34.

6. Laine K, Skjeldestad FE, Sanda B, et al. Prevalence and risk factors for anal incontinence after obstetric anal sphincter rupture. Acta Obstet Gynecol Scand 2011:90:319-24.

7. Bols EM, Hendriks EJ, Berghmans BC, et al. A systematic review of etiological factors for postpartum fecal incontinence. Acta Obstet Gynecol Scand 2010;89:302-14.

8. Norderval S, Nsubuga D, Bjelke C, et al. Anal incontinence after obstetric sphincter tears: incidence in a Norwegian county. Acta Obstet Gynecol Scand 2004;83:989-94.

9. de Leeuw JW, de Wit C, Kuijken JP, et al. Mediolateral episiotomy reduces the risk for anal sphincter injury during operative vaginal delivery. BJOG 2008;115:104-8.

10. Räisänen $\mathrm{SH}$, Vehviläinen-Julkunen $\mathrm{K}$, Gissler M, et al. Lateral episiotomy protects primiparous but not multiparous women from obstetric anal sphincter rupture. Acta Obstet Gynecol Scand 2009;88:1365-72.

11. Räisänen S, Vehviläinen-Julkunen $\mathrm{K}$, Gissler M, et al. High episiotomy rate protects from obstetric anal sphincter ruptures: a birth register-study on delivery intervention policies in Finland. Scand J Public Health 2011;39:457-63.

12. Dahl C, Kjolhede P. Obstetric anal sphincter rupture in older primiparous women: a case-control study. Acta Obstet Gynecol Scand 2006;85:1252-8.

13. Bowling CB, Wheeler Ii TL, Gerten KA, et al. Sphincter tears in primiparous women: is age a factor? Int Urogynecol J Pelvic Floor Dysfunct 2008;179:600-4.
14. Gerdin E, Sverrisdottir G, Badi A, et al. The role of maternal age and episiotomy in the risk of anal sphincter tears during childbirth. Aust N Z J Obstet Gynaecol 2007;47:286-90.

15. Räisänen $S$, Vehviläinen-Julkunen K, Gissler M, et al. The increased incidence of obstetric anal sphincter rupture-an emerging trend in Finland. Prev Med 2009;49:535-40.

16. Ekeus C, Nilsson E, Gottvall K. Increasing incidence of anal sphincter tears among primiparas in Sweden: a population-based register study. Acta Obstet Gynecol Scand 2008;87:564-73.

17. Laine K, Pirhonen T, Rolland R, et al. Decreasing the incidence of anal sphincter tears during delivery. Obstet Gynecol 2008;111:1053-7.

18. Hals E, Øian P, Pirhonen T, et al. A multicenter interventional program to reduce the incidence of anal sphincter tears. Obstet Gynecol 2010;116:901-8.

19. Roos AM, Thakar $\mathrm{R}$, Sultan $\mathrm{AH}$. Outcome of primary repair of obstetric anal sphincter injuries (OASIS): does the grade of tear matter? Ultrasound Obstet Gynecol 2010;36:368-74.

20. Coats PM, Chan KK, Wilkins M, et al. A comparison between midline and mediolateral episiotomies. Br J Obstet Gynaecol 1980;87:408-12.

21. Hirsch E, Haney El, Gordon TE, et al. Reducing high-order perineal laceration during operative vaginal delivery. Am J Obstet Gynecol 2008;198:668.e1,668.e5.

22. Jönsson ER, Elfaghi I, Rydhström H, et al. Modified Ritgen's maneuver for anal sphincter injury at delivery: a randomized controlled trial. Obstet Gynecol 2008;112:212-17.

23. McCandlish $\mathrm{R}$, Bowler U, van Asten $\mathrm{H}$, et al. A randomised controlled trial of care of the perineum during second stage of normal labour. Br J Obstet Gynaecol 1998;105:1262-72.

24. Mayerhofer K, Bodner-Adler B, Bodner K, et al. Traditional care of the perineum during birth. A prospective, randomized, multicenter study of 1,076 women. J Reprod Med 2002;47:477-82.

25. Albers LL, Sedler KD, Bedrick EJ, et al. Midwifery care measures in the second stage of labor and reduction of genital tract trauma at birth: a randomized trial. J Midwifery Womens Health 2005;50:365-72.

26. de Leeuw JW, Struijk PC, Vierhout ME, et al. Risk factors for third degree perineal ruptures during delivery. BJOG 2001;108:383-7.

27. Räisänen $\mathrm{S}$, Vehviläinen-Julkunen $\mathrm{K}$, Gissler $\mathrm{M}$, et al. Hospital-based lateral episiotomy and obstetric anal sphincter injury rates: a retrospective population-based register study. Am J Obstet Gynecol 2012;206:347.e1,347.e6.

28. Zafran N, Salim R. Impact of liberal use of mediolateral episiotomy on the incidence of obstetric anal sphincter tear. Arch Gynecol Obstet 2012;286:591-7.

29. Williams A, Tincello DG, White $S$, et al. Risk scoring system for prediction of obstetric anal sphincter injury. BJOG 2005;112:1066-9.

30. Harkin R, Fitzpatrick M, O'Connell PR, et al. Anal sphincter disruption at vaginal delivery: is recurrence predictable? Eur J Obstet Gynecol Reprod Biol 2003;109:149-52.

31. Varma A, Gunn J, Lindow SW, et al. Do routinely measured delivery variables predict anal sphincter outcome? Dis Colon Rectum 1999;42:1261-4. 